\title{
Speech Processor Device
}

National Cancer Institute

\section{Source}

National Cancer Institute. Speech Processor Device. NCI Thesaurus. Code C50306.

An electronic device designed to convert speech sounds into electrical signals, especially as part of a cochlear implant. 